\title{
Seismic Response Evaluation of High-Rise Building with and Without Fluid Viscous Damper
}

\author{
Khalil Yahya Mohammed Almajhali*, Bin Xu, Qingxuan Meng \\ School of Mechanics, Civil Engineering and Architecture, Northwestern Polytechnical University, Xi'an, China \\ Email address: \\ engkhalil16@yahoo.com (K.Y.M. Almajhali) \\ ${ }^{*}$ Corresponding author \\ To cite this article: \\ Khalil Yahya Mohammed Almajhali, Bin Xu, Qingxuan Meng. Seismic Response Evaluation of High-Rise Building with and Without \\ Fluid Viscous Damper. American Journal of Civil Engineering. Vol. 6, No. 5, 2018, pp. 167-177. doi: 10.11648/j.ajce.20180605.15
}

Received: August 26, 2018; Accepted: December 10, 2018; Published: December 24, 2018

\begin{abstract}
The major lateral load of the high structures is the earthquake load. In the high rise buildings, the structural response increases exponentially in response to earthquake load. Therefore, the damping has significant function in design of Earthquake Resistant High Structures, which can decrease the response of the structure when exposed to lateral loads. The energy produced by earthquake will be absorbed by these devices and the load acting on the main structure of the building will reduce significantly. The fluid viscous dampers are used to dissipate energy and lessen the response of reinforced concrete buildings. The main function of structure is to carry the lateral loads and transmit them well to the foundation. The lateral loads enjoined on the structures are dynamic in nature, which cause vibrations in the structure. In the current study, the responses of the structures having square plans with different cross-sections are analyzed by the software ETABS 2015 based on the consideration of Fluid Viscous Damper. The results of numerical examples show that fluid viscous damper (250) can reduce the response of the structures effectively, including the base shear of the buildings, and the structures with square columns performs perfect and have good earthquake resistant characteristics when compared to structures with rectangular columns regardless of the flooring plan.
\end{abstract}

Keywords: Fluid Viscous Dampers, Square Plans, Rectangular and Square Columns, Seismic Response from Time History, Base Shear

\section{Introduction}

Over the past decades, the world has witnessed many earthquakes that caused the death of many people and the destruction of many residential buildings. Therefore, the occurrence of such damage generally shows the seriousness of earthquakes on the structures. The dampers are one of the means that play a role in the dissipation of energy created by earthquakes and transfer to foundations.

The fluid viscous dampers (FVD) are one of the applied equipment for controlling responses of the high-rise buildings. This equipment is applied based on different structures technologies in order to reduce structural responses to earthquakes excitation [1]. Over the last sixty years, the earthquakes are classified into various categories one of which is near field earthquakes from the source. Later, such definition has been modified in addition to other factors that affected this categorization.

During the recent years, the research has been concentrated on the study of influences of ground motion on the structural performance in these earthquakes that are close to the field. The destructive effects of the recent decades earthquakes such as North Yemen earthquake (1982), Kobe earthquake (1995), and Taiwan earthquake (1999) on the structure of the cities adjoining to fault, and with regard to the location of Yemen to the active fault indicates the importance of the research.

Over recent few years, many important developments in the field of seismic codes were turned up. Due to the renovated knowledge of the existing structures behavior, the retrofit of buildings is an essential task in decreasing seismic hazard. New techniques have been developed for the protection of buildings to withstand earthquakes with the aim of improving their ability. Energy dissipation and seismic isolation are vastly recognized as effectual 
protection techniques for getting the performance aims of modern codes [2]. Energy dissipation involves factors such as radiation of soil, materials etc. A clear understanding of the damping is required in order to integrate its effect on the structure. The form of response curve does not change through damping but the amplitudes are decreased [3].

Structural analysis is defined as the judgment of the impact of loads on structures and all their segments. Structures, which subject or undergo to this type of analysis, include all that must resist loads, such as structures, bridges, machinery, vehicles, attire, furniture, prostheses and biological tissue. The scope of structural analysis ranges of materials science, applied mechanics and applied mathematics to calculate a structure's deformations, stresses, internal forces, accelerations, support reactions, and stability. The results of the analysis are used to check a structural strength for use, where physical tests are often prevented. Structural analysis is considered as the main component or key in designs of engineering structures as described by K. H. Chang in 2009 [4].

T. Ono and Y. G. Zhao 2001 have mentioned about "Moment methods for structural reliability" where it is illustrated that to implement an accurate analysis, the designer engineer must specify all information such as structural loads, support conditions, geometry and materials properties. The results of this analysis typically involve support reactions, displacements and stresses. This information is compared to criteria that refer to failure conditions. Advanced structural analysis may check dynamic response, non-linear behavior and stability [5].

K. Venkataramana, V. Umachagi, R. Verma, and G. R. Reddy in "Applications of Dampers for Vibration Control of Structures" briefly demonstrated that Fluid Viscous dampers work is based on flow through the orifices. Stefano et al., in 2010 implemented three floor structure for seismic control of construction with extra viscous damper. Attar et al., in 2007 have suggested optimal viscous damper for reducing the inter-story displacement of steel structure [6].

Özgur Atlayan, in 2008 "Effect of Viscous Fluid Dampers on Steel Moment Frame Designed for Strength and Hybrid Steel Moment Frame Design," have investigated that the damping of the building increases with the assistance of added dampers, and the structural response becomes better. Maximum and inter-story drifts, residual roof displacements, and Incremental Dynamic Analysis (IDA) dissipation reduces with increasing damping. In addition, by utilizing supplementary damping, most of the collapses that happen for the naturally damped structures are prevented [7].

\subsection{Objective of the Research}

To execute the comparison of the seismic response between square buildings with square column and those with rectangular column, with Fluid Viscous Dampers and without Fluid Viscous Dampers.

To study the differences in time period for various structures with Fluid Viscous Dampers and without Fluid Viscous Dampers.

\subsection{General Description About Software and Fluid Viscous Damper ETABS}

ETABS is one of the engineering software products, which serves to multi-story buildings analysis and design. Basic or advanced systems beneath static conditions or dynamic conditions can be assessed using ETABS. For an advanced assessment of seismic response performance, Nonlinear links and concentrated fiber hinges or PMM may take material nonlinearity under hysteretic or monotonic behavior. Integrated and intuitive features make applications of any complications effective to implement. Interoperability with a series of design and documentation platforms makes ETABS a productive and coordinated tool for analysis and designs which extent from simple 2D framework to elaborated modernistic high-rises.

Some of the key features of ETABS are given as:

It is based on the theory of finite elements dedicated to the analysis and design of structural sentences of buildings exclusively. It also contains distinctive features that are interoperable with other regarding software products, which include the import of models or architectural designs from different technical drawing software's, or export to several platforms. It is also the practical option for all of the grid-like applications extending from simple twodimension framework to the most complex high rises. In the Fluid Viscous Damper, energy is dissipated due to ease of inauguration, coordination and adaptability inside a cylinder by using viscous fluid. With numerous members, varieties and sizes, viscous dampers have several applications in each of designing and retrofitting. These sorts of dampers are connected to the building in three ways:

1. The dampers installed in the foundations or floor (by seismic isolation method).

2. Connecting dampers in strong pericardial braces.

3. The dampers installed in diagonal braces.

\section{Methodology}

The natural frequencies of a system are only dependent on the mass and the stiffness of the structure. They do not depend on the load function.

A modal analysis computes the natural frequencies or modes of a specific system, however not necessarily its entire-time history response to specific input.

It is beneficial to know about dynamic characteristics of structures to be ensured that the frequency of any used periodic loading shall not synchronize with a modal frequency and cause resonance, which often leads to large oscillations.

The above-mentioned method consists of three steps:

1. Detection of natural modes (the shape adopted by a frame or structure) and each of concerned natural frequencies. 
2. Computation of the response corresponding to every mode.

3. Optionally, the superposition of the response of every mode to find the whole modal response to a specific loading.

\section{Statement of the Problem}

The dynamic can be defined as time changing; therefore, a dynamic load means that its direction, magnitude, and/or position changes with time. Likewise, the response of structures under dynamic loads, i.e., the resulting deflections and stresses, is also time altering, or dynamic [8].

High building in an area of high winds and high seismicity must be accurately designed to ensure the sufficient balance between strength and stiffness. Conventional practice is to strengthen a structure in order to decrease the dynamic response under earthquake loading or wind loading. Although, this has the impact on increasing the seismic base shear. Through adding supplementary damping in tall buildings, it is possible to lessen the flexural stiffness of the structure to reduce seismic base shear, and at the same time to control the structural response under earthquake.

\section{Time History Analysis Processes Mode Superposition Method}

\subsection{Compaction of Modal Matrix}

$$
[m][\ddot{x}]+[c][\dot{x}]+[k][x]=-\ddot{x}_{g(t)}[m]\{I\}
$$

Where $[m],[c],[k]$ are system mass, damping and stiffness matrixes respectively; $\ddot{x}_{g(t)}$ is ground acceleration and $\{I\}$ is a unit vector. Where $[\ddot{x}],[\dot{x}],[x]$ are the acceleration, velocity and displacement vectors respectively.

$$
\{x\}=[\phi]\{q\}
$$

Where $[\phi]$ is the modal matrix and $\{q\}$ is the modal displacement vector. Due to the solution of equation of motion for any specific forces is hard to obtain, the mode superposition method is used. In modal analysis, a set of normal coordinates i.e. Principal coordinates is defined, to uncouple the equation of motion in physical space. Then, we have;

$$
\begin{aligned}
& \{\dot{x}\}=[\phi]\{\dot{q}\} \\
& \{\ddot{x}\}=[\phi]\{\ddot{q}\}
\end{aligned}
$$

After substituting, Eq. (2) (4) into Eq. (1) and multiplying both sides by

$$
[\phi]^{T}[m][\phi][\ddot{q}]+[\phi]^{T}[c][\phi][\dot{q}]+[\phi]^{T}[k][\phi][q]
$$

$$
=\left[-\ddot{x}_{g(t)}\right][\phi]^{T}[m]\{I\}
$$

Eq. (6)can be rewritten as

$$
[M][\ddot{q}]+[C][\dot{q}]+[K][q]=\left[P_{\text {eff }(t)}\right]
$$

Where the diagonalized modal mass matrix $[M]=$ $[\phi]^{T}[m][\phi]$; the digonalized modal damping matrix $[C]=$ $[\phi]^{T}[c][\phi]$; the diagonalized modal stiffness $[K]=$ $[\phi]^{T}[k][\phi]$; the effective modal force vector

$$
\begin{aligned}
& {\left[P_{\text {eff }(t)}\right]=-\ddot{x}_{g(t)}[\phi]^{T}[m]\{I\} ;} \\
& {[\phi]=\left[\phi_{1}, \phi_{2}, \phi_{3}, \ldots \ldots \ldots, \phi_{n}\right] ;} \\
& \{q\}=\left\{q_{1}, q_{2}, q_{3}, \ldots \ldots \ldots, q_{n}\right\}^{T}
\end{aligned}
$$

where $n$ is the number of extracted modes.

Then the ith natural frequency $\omega_{i}$ and the corresponding mode shape can be computed by the following equation

$$
\left[k-\omega_{i}^{2} m\right]=\phi_{i}=0
$$

If the mode shapes satisfy the normalized orthogonal conditions, we can obtain;

$$
\begin{gathered}
{[M]=[\phi]^{T}[m][\phi]=\operatorname{Diag}\{1\}} \\
{[K]=[\phi]^{T}[k][\phi]=\operatorname{Diag}\left\{\omega_{i}{ }^{2}\right\}} \\
{[C]=[\phi]^{T}[c][\phi]=\operatorname{Diag}\left\{2 \xi_{i} \omega_{i}\right\}}
\end{gathered}
$$

Where is the ith mode damping ratio $\xi_{i} \frac{C}{2 \omega_{i}}$

\subsection{Calculation of Effective Force Vector}

$$
\left[P_{\text {eff }(t)}\right]=-\ddot{x}_{g(t)}[m]\{I\}=-\ddot{x}_{g(t)}\left[\gamma_{i}\right]
$$

Where $\gamma_{r}=\phi_{i}^{T}[m]\{I\}$

\subsection{Calculation of Displacement Response in Mode Space}

The uncoupled equations coupled in mode space are given

$$
\begin{gathered}
\ddot{q}_{i}+2 \xi_{i} \omega_{i} q_{i}+\omega_{i}{ }^{2} q_{i}=-\ddot{x}_{g(t)} r_{i} \\
i=1,2, \ldots \ldots \ldots, n
\end{gathered}
$$

These equations can be solved using Newmark's Method.

\subsection{Computation of Displacement in Physical Space}

$$
\left\{x_{(t)}\right\}=\sum_{i=1}^{n} \phi_{i}{ }^{T} q_{i}(t) i=1,2, \ldots \ldots \ldots, n
$$

\subsection{Computation of Effective Earthquake Response Forces}

While the relative displacement of the modes has been determined, the effective earthquake force or the elastic restoring force $\mathrm{F}$ acting at each mode $\mathrm{m}$ is determined from

$$
F_{s(t)}=[k]\left\{x_{(t)}\right\}
$$


The analysis of ETABS 2015 includes

1. Modelling

2. Static analysis

3. Design

4. Response spectrum analysis

\section{Structural Elements}

The structural elements studied are columns and beams with variable sections as mentioned below;

Description of Members, which are used:

Column Sizes:

1. Square Columns $=550 \mathrm{~mm} * 550 \mathrm{~mm}$.

2. Rectangular Columns $=1100 \mathrm{~mm} * 300 \mathrm{~mm}$.

Beam Sizes:

1. Interior Beams $=250 \mathrm{~mm} * 600 \mathrm{~mm}$.

2. Exterior Beams $=300 \mathrm{~mm} * 700 \mathrm{~mm}$.

Slab Sizes:

1. Panel Area $=5 \mathrm{~m} * 5 \mathrm{~m}=25 \mathrm{~m}^{2}$

2. Thickness $=140 \mathrm{~mm}$

Loads

During the application of the loads to the building, only the external loads are considered, which are in effect acting on the all members neglecting its self-weight. In ETABS 2015.2.0, it automatically takes into consideration of the members self-weight.

The loads on Slabs effective in the gravity direction are Dead Load $=2 \mathrm{kN} / \mathrm{m}^{2}$ and Live Load $=3 \mathrm{kN} / \mathrm{m}^{2}$. The Framework loads have been applied uniformly on the Exterior Beams as Dead $=11.61 \mathrm{kN} / \mathrm{m}$ and Interior Beams as Dead $=8.64 \mathrm{kN} / \mathrm{m}$.

The Seismic loads Earthquake-X and Earthquake-Y are given in (Load patterns) directly using Code UBC97 under El Centro Earthquake for all models.
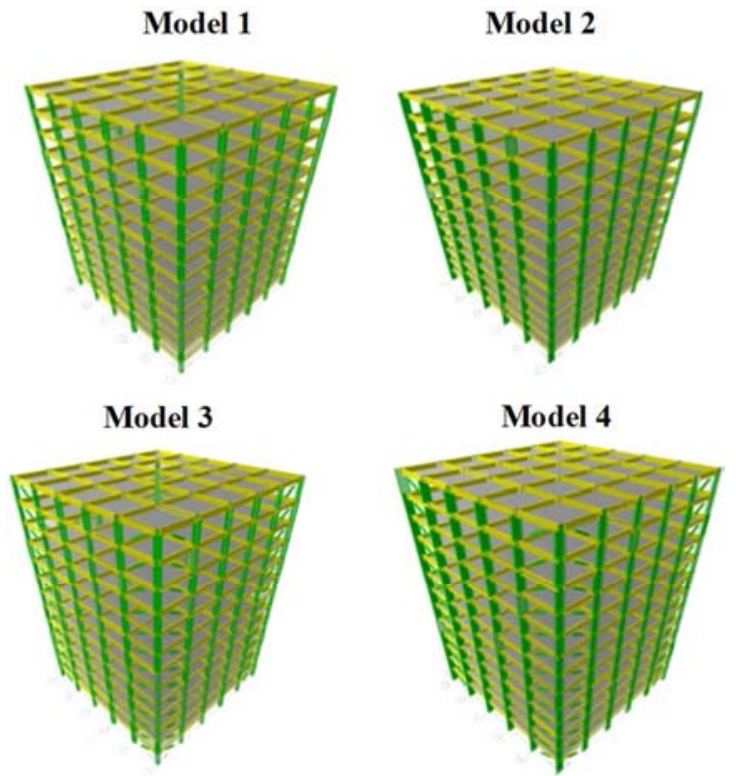

Figure 1. Model 1: Building with Square Column no damper; Model 2: Building with Rectangular Column no damper; Model 3: Building with Square column with fluid viscous damper; Model 4: Building with Rectangular column with fluid viscous damper.
Model 1

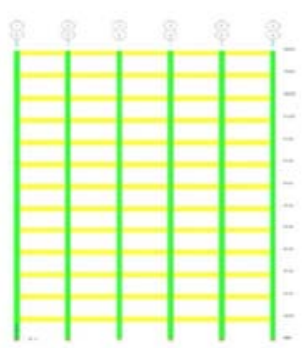

Model 3

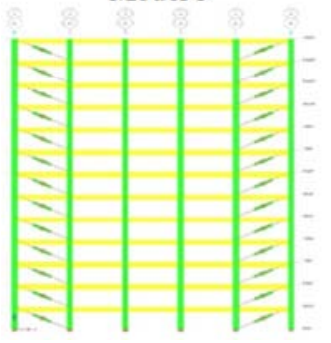

Model 2

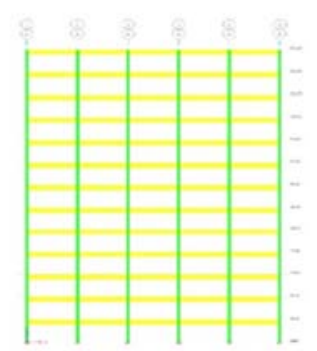

Model 4

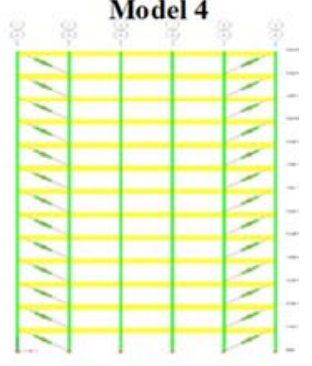

Figure 2. Model 1: Building with square column no damper (section); Model 2: Building with Rectangular column no damper (section); Model 3: Building with Square column with fluid viscous damper (section); Model 4: Building with Rectangular column with fluid viscous damper (section).

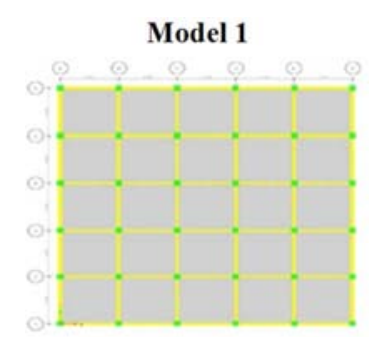

Model 3

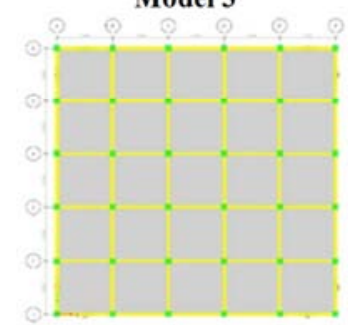

Model 2

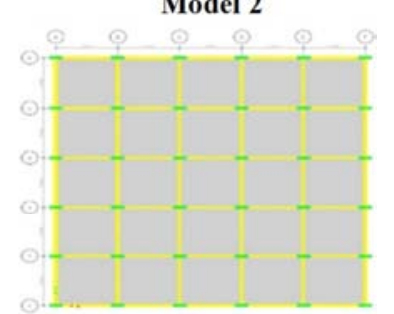

Model 4

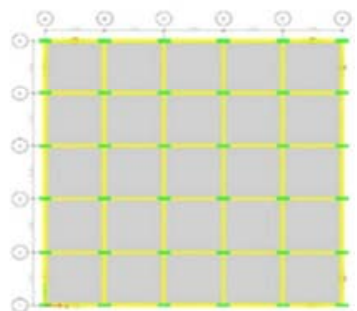

Figure 3. Model 1: Building with square column no damper (plan); Model 2: Building with Rectangular column no damper (plan); Model 3: Building with Square column with fluid viscous damper (plan); Model 4: Building with Rectangular column with fluid viscous damper (plan).

\section{Result and Discussion}

\subsection{Response Spectrum Form}

This following table 1 shows the response results at a specific point for a specific time history analysis load case.

Table 1. Input Data.

\begin{tabular}{llll}
\hline Name & \multicolumn{2}{l}{ RS From Time History1 } & \\
\hline Load Case & Time History-X & Coordinate System & Modal \\
Story & Story13 & Response Direction & X \\
Point & 1 & Spectrum Widening & $0 \%$ \\
\hline
\end{tabular}




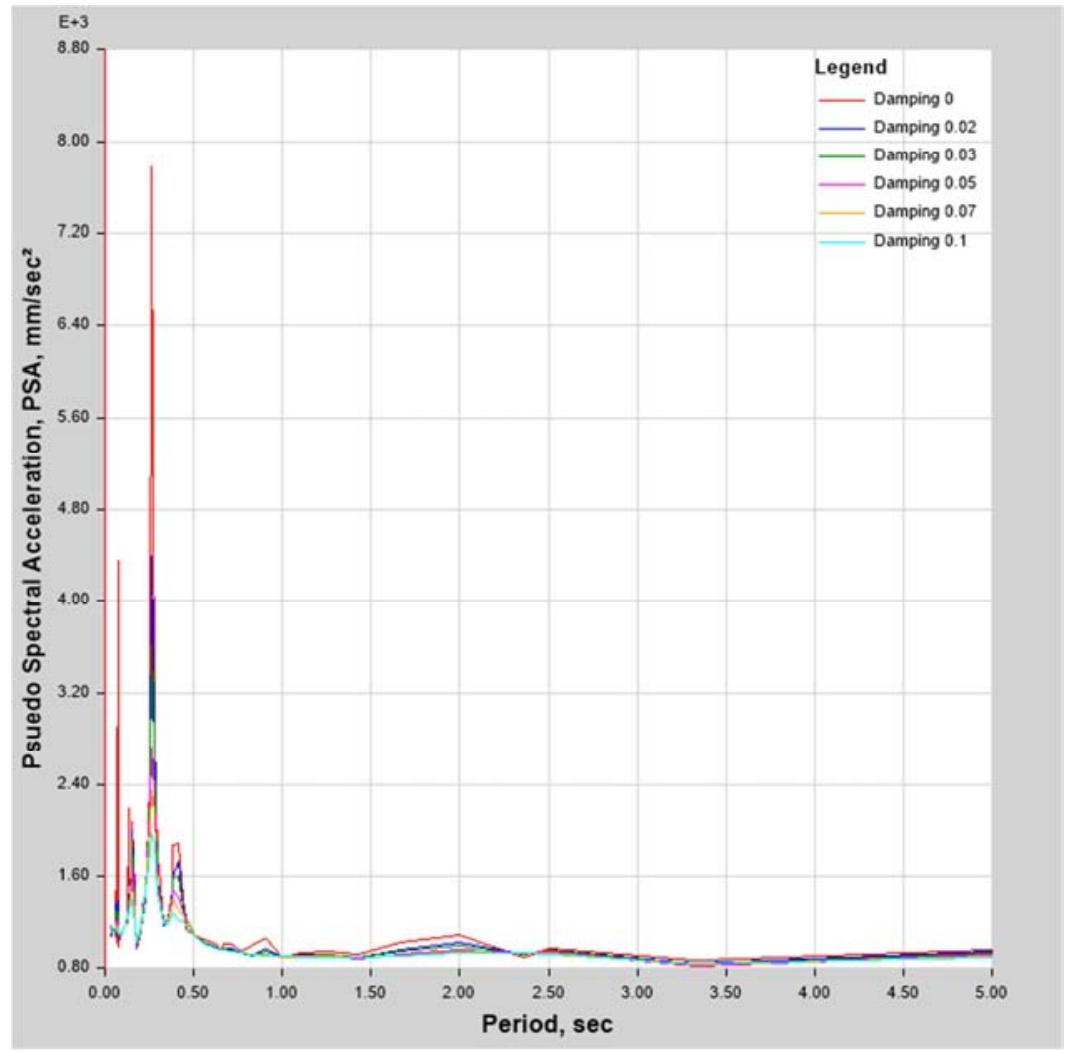

Figure 4. Response Spectrum curves for Square Building Square Column with different damping ratio and without FVD.

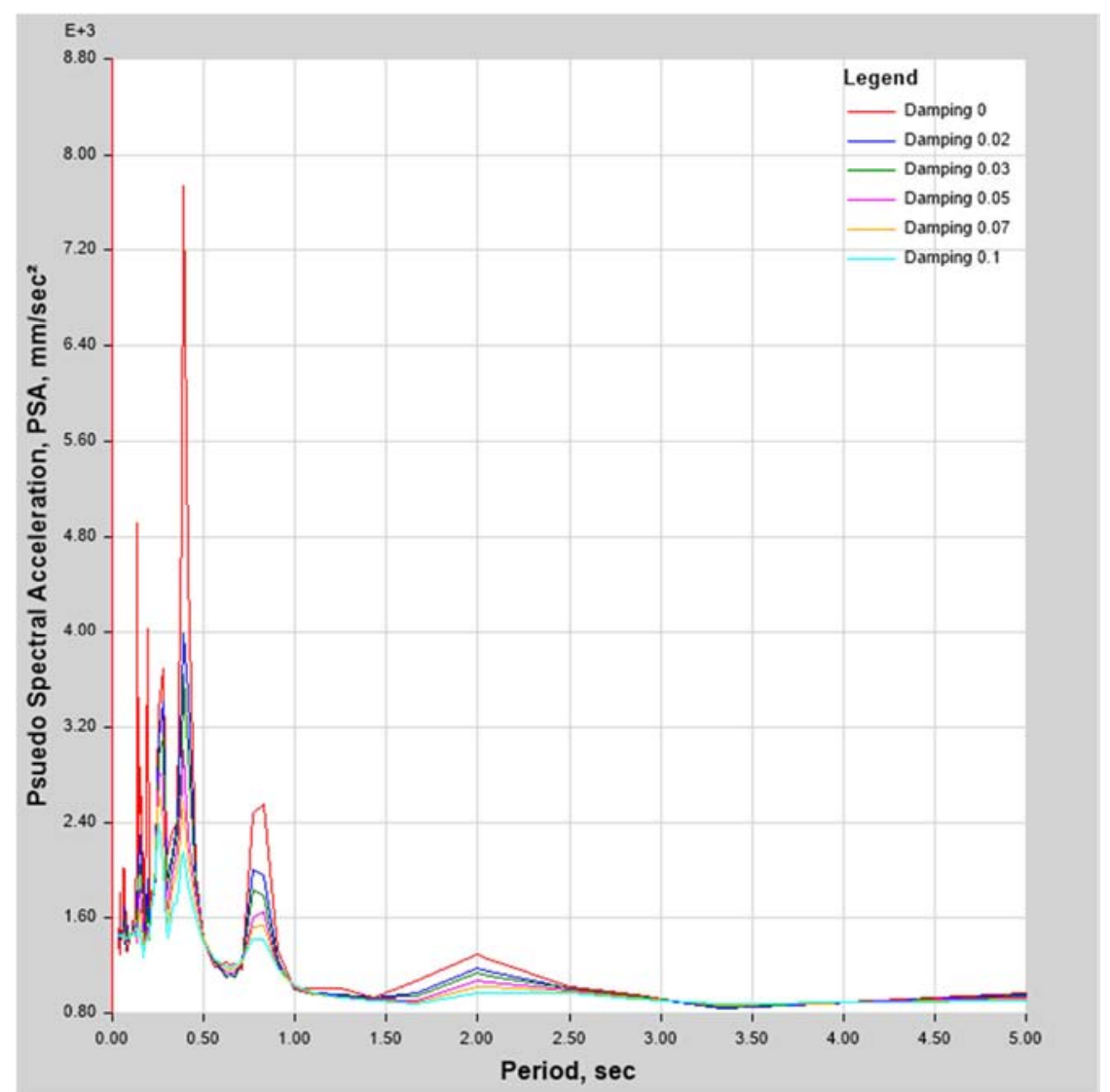

Figure 5. Response Spectrum curves for Square Building Rectangular Column with different damping ratio and without FVD. 

Without Fluid Viscous Damper

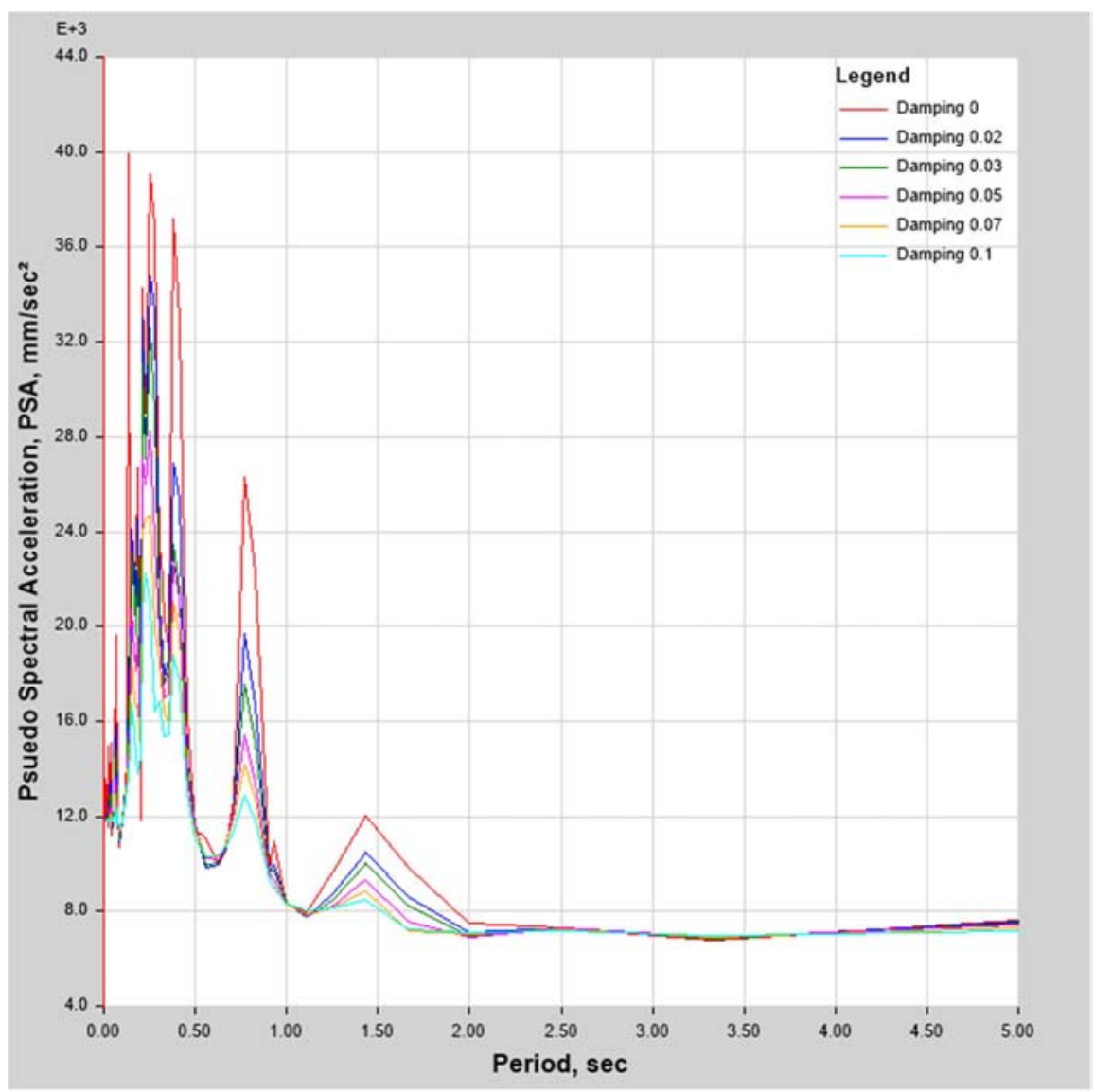

Figure 6. Response Spectrum curves for Square Building Square Column with different damping ratio and FVD.

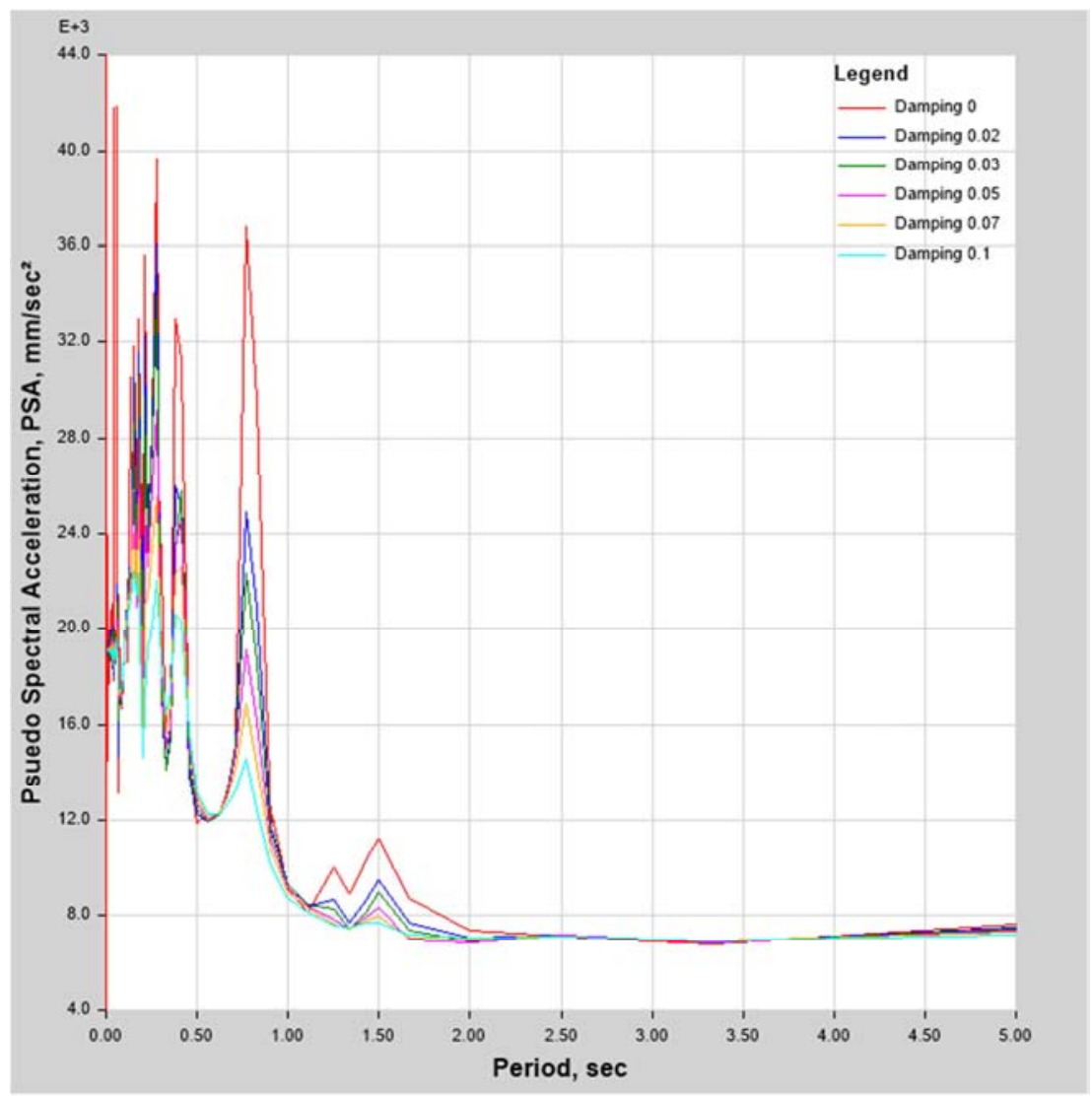

Figure 7. Response Spectrum curves for Square Building Rectangular Column with different damping ratio and FVD. 
Table 2. Maximum Pseudo Spectral Acceleration at (Zero Damping) under El Centro earthquake.

\begin{tabular}{|c|c|c|c|c|}
\hline \multirow{2}{*}{ Max. Values } & \multicolumn{4}{|c|}{ Load Case / Direction } \\
\hline & \multicolumn{2}{|c|}{ Time History $\mathbf{X} / \mathbf{X}$} & \multicolumn{2}{|c|}{ Time History Y/Y } \\
\hline Building Modal & Period (sec) & PSA $\left(\mathrm{mm} / \mathrm{sec}^{2}\right)$ & Period (sec) & PSA $\left(\mathrm{mm} / \mathrm{sec}^{2}\right)$ \\
\hline SBSC without FVD & 0.261 & 7774.42 & 0.261 & 7774.57 \\
\hline SBRC without FVD & 0.39 & 7740.29 & 0.278 & 1853.98 \\
\hline SBSC with FVD & 0.133 & 38945.6 & 0.133 & 38945.6 \\
\hline SBRC with FVD & 0.061 & 42866.8 & 0.061 & 40535.67 \\
\hline
\end{tabular}

$\mathrm{x}$ axis $\mathrm{y}$ axis

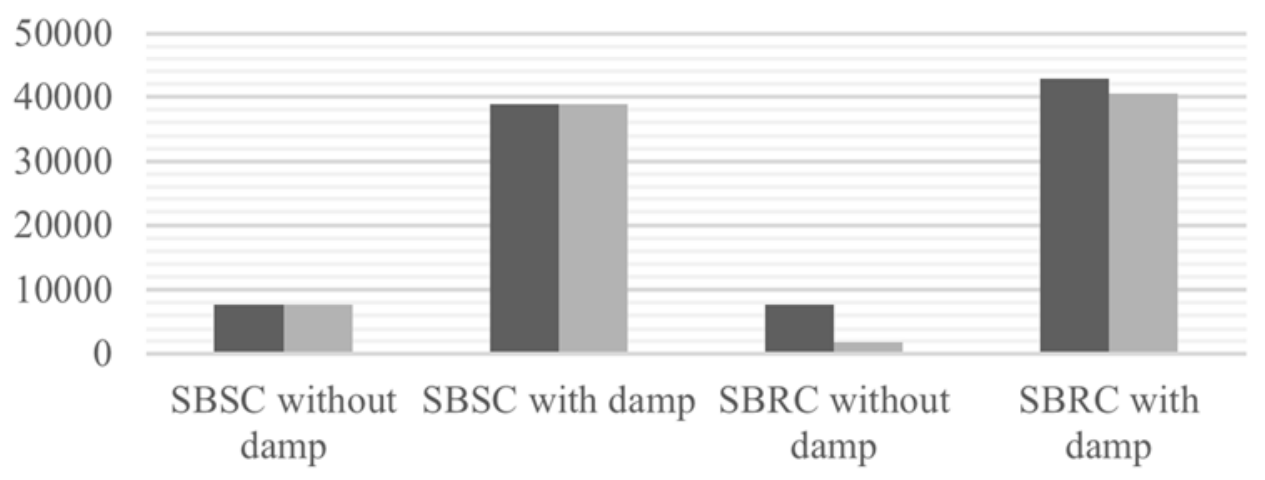

Figure 8. Maximum PSA at Zero Damping under El Centro earthquake.

\subsection{Pseudo Spectral Acceleration from Response Spectrum Curves}

Pseudo-velocity response spectra and Velocity are different for systems with high damping ratios and long periods and are not interchangeable. For high periods, Response spectrum values are very precisely sensitive to site provisions and source. Hence, the buildings with Fluid Viscous Damper have less cyclic (periodic) values leading to override the maximum Pseudo Spectral Acceleration values during the un-cracked time period, as displayed in table 2 .

It can be seen that the symmetrical structure like Square building with Square Column displays low periodic values with or without fluid viscous damper, whereas Square building with Rectangular Column displays long periodic values without fluid viscous damper for maximum Pseudo Spectral Acceleration, which is sensitive. This building shows $81.94 \%$ reduction in periodic values by using Fluid Viscous for Square Building with Rectangular Column.

Table 3. Base Reactions of Square Building with Square Column.

\begin{tabular}{|c|c|c|c|c|c|c|}
\hline \multirow{2}{*}{ Load Case/Combo } & FX & FY & FZ & MX & MY & MZ \\
\hline & $\mathbf{k N}$ & $\mathbf{k N}$ & $\mathbf{k N}$ & kN-m & kN-m & kN-m \\
\hline Dead & 0 & 0 & 104521.4 & 1306518 & -1306518 & 0 \\
\hline Live & 0 & 0 & 24375 & 304687.5 & -304688 & 0 \\
\hline EQ-X & -9978.41 & 0 & 0 & 0 & -277625 & 124730.1 \\
\hline EQ-Y & 0 & -9978.41 & 0 & 277625 & 0 & -124730 \\
\hline Time-History-X Max & 10063.74 & 0 & 0 & 0.0004 & 204536.2 & -30.6097 \\
\hline TimeHistory-X Min & 2.4488 & -0.0004 & 0 & $-4.29 \mathrm{E}-06$ & 0 & -125797 \\
\hline Time-History-Y Max & 0.0001 & 10063.93 & 0 & 0 & 0.0001 & 125799.1 \\
\hline Time-History-Y Min & $-2.28 \mathrm{E}-06$ & 2.4488 & 0 & -204540 & -0.0001 & 30.6103 \\
\hline
\end{tabular}

Table 4. Base Reactions of Square Building with Rectangular Column.

\begin{tabular}{|c|c|c|c|c|c|c|}
\hline \multirow{2}{*}{ Load Case/Combo } & $\mathbf{F X}$ & FY & $\mathbf{F Z}$ & MX & MY & MZ \\
\hline & $\mathbf{k N}$ & $\mathbf{k N}$ & $\mathbf{k N}$ & kN-m & kN-m & kN-m \\
\hline Dead & 0 & 0 & 104962.5 & 1312032 & -1312032 & 0 \\
\hline Live & 0 & 0 & 24375 & 304687.5 & -304688 & 0 \\
\hline EQ-X & -10015.2 & 0 & 0 & 0 & -278585 & 125189.7 \\
\hline EQ-Y & 0 & -10015.2 & 0 & 278584.7 & 0 & -125190 \\
\hline Time-History-X Max & 10136.42 & 0 & 0 & 0.0003 & 202299.1 & -33.7973 \\
\hline TimeHistory-X Min & 2.7038 & -0.0001 & 0 & 0 & 0 & -126705 \\
\hline Time-History-Y Max & 0.0003 & 10128.78 & 0 & 0 & 0.0003 & 126609.8 \\
\hline Time-History-Y Min & 0 & 2.7038 & 0 & -208148 & 0 & 33.7973 \\
\hline
\end{tabular}


Table 5. Base Reactions of Square Building with Square Column with FVD.

\begin{tabular}{|c|c|c|c|c|c|c|}
\hline \multirow{2}{*}{ Load Case/Combo } & FX & FY & FZ & MX & MY & MZ \\
\hline & $\mathbf{k N}$ & $\mathbf{k N}$ & $\mathbf{k N}$ & kN-m & kN-m & kN-m \\
\hline Dead & 0 & 0 & 112688.6 & 1408607 & -1408607 & 0 \\
\hline Live & 0 & 0 & 22547.54 & 281844.3 & -281844 & 0 \\
\hline EQ-X & 1057.456 & 0 & 0 & 0 & -63281.7 & -13218.2 \\
\hline EQ-Y & 0 & 1057.456 & 0 & 63281.73 & 0 & 13218.2 \\
\hline Time-History-X Max & 1057.456 & 9.91E-06 & 0 & 0.0002 & 302893 & 81008.89 \\
\hline TimeHistory-X Min & -6480.71 & $-9.94 \mathrm{E}-06$ & 0 & -0.0002 & -1147.08 & -899.876 \\
\hline Time-History-Y Max & $1.00 \mathrm{E}-05$ & 1057.456 & 0 & 1147.084 & 0.0002 & 899.876 \\
\hline Time-History-Y Min & $-2.14 \mathrm{E}-05$ & -6480.71 & 0 & -302893 & -0.0005 & -81008.9 \\
\hline
\end{tabular}

Table 6. Base Reactions of Square Building with Rectangular Column with FVD.

\begin{tabular}{lllllll}
\hline \multirow{2}{*}{ Load Case/Combo } & FX & FY & FZ & MX & MY & kZ \\
\cline { 2 - 6 } & $\mathbf{k N}$ & $\mathbf{k N}$ & $\mathbf{k N}$ & $\mathbf{k N}$ & $\mathbf{k}$ \\
\hline Dead & 0 & 0 & 113046.4 & 1413080 & -1413080 \\
Live & 0 & 0 & 22568.92 & 282111.5 & -282111 \\
EQ-X & 3771.946 & 0 & 0 & 0 & -64118.3 \\
EQ-Y & 0 & 318.8374 & 0 & 42586.93 & 0 \\
Time-History-X Max & 3771.946 & 0 & 0 & $5.59 \mathrm{E}-07$ & 305725.1 \\
TimeHistory-X Min & -22601.1 & 0 & 0 & $-1.73 \mathrm{E}-05$ & -1103.81 \\
Time-History-Y Max & 0 & 3771.946 & 0 & 1568.169 & 0 \\
Time-History-Y Min & $-9.96 \mathrm{E}-06$ & -1903.69 & 0 & -195458 & -47149.3 \\
\hline
\end{tabular}

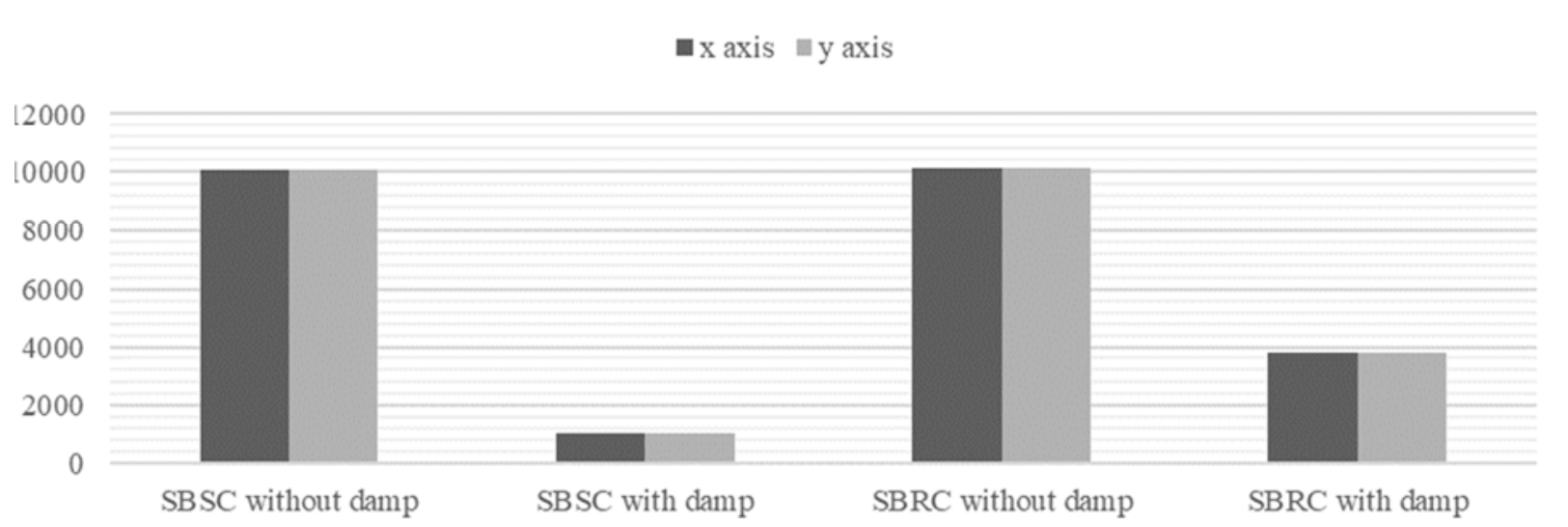

Figure 9. BASE SHEAR $(\mathrm{kN})$.

From the comparison results in figure 9, it can be found that due to entry of Fluid Viscous Damper in the buildings, the base shear has been reduced by $89.49 \%$ for Square Building with Square Column, 62.79\% for Square Building with Rectangular Column in Time History-X/ X-direction. In a similar way, the base shear has been diminished by $89.49 \%$ for Square Building with Square Column, 62.34\% for Square Building with Rectangular Column in Time History-Y/ Y-direction.

\subsection{Modal Participating Mass Ratios}

A modal analysis is one of analysis technique to calculate the linear response of buildings to dynamic loading. In modal analysis, we can decompose the response of the building to parts of vibration modes. A mode is defined by means of its frequency and shape. The structural engineers call on the modes with the shortest frequencies (the longest periods) as the fundamental modes through dynamic loading, i.e. earthquake, blast loading or wind. Not all modes are stimulated in the same conduct. The excitation extent of the dynamic loading of the specified vibration modes depends on frequency content of load and the spatial distribution.

Participating Modal Mass Ratio is oscillating mass anticipation, and Effective Modal Mass is an effective magnitude of a sort of oscillation. Participating Modal Mass Ratio-Oscillating mass participation, according to instructions reference analysis of (CSI), Participating Modal Mass Ratio is given as follow

$$
\text { Modal Participating Mass Ratios }=\frac{\left(\sum_{j=1}^{n} m_{j} \phi_{j, i}\right)^{2}}{\left(\sum_{j=1}^{n} m_{j}\right)}
$$

\subsection{Effective Volume \& Effective Modal Mass}

The vibration pattern effective mass is determined by the equation

$$
M_{t d, i}=\frac{\left(\sum_{j=1}^{n} m_{j} * \phi_{j, i}\right)^{2}}{\left(\sum_{j=1}^{n} m_{j}\right)}
$$

A percentage of the overall magnitude is as follows: 


$$
\% M_{t d, i}=\frac{\left(\sum_{j=1}^{n} m_{j} * \phi_{j, i}\right)^{2}}{\left(\sum_{j=1}^{n} m_{j} * \phi_{j, i}\right)^{2} *\left(\sum_{j=1}^{n} m_{j}\right)}
$$

Mathematically, oscillating mass participationParticipating Modal Mass Ratio (MPMR) was used to evaluate the level of importance of an oscillating shape and the shape of these oscillations. Effective volume (EMM) or proportion effective volume\% Effective volume (EMM) is used to calculate those loads that are carried on the seismic constructional system. Multiple Degrees Of Freedom is based on the calculation of load effects. The significant earthquake has a single degree of freedom system (SDOF) with the same mass and oscillation cycle. Mathematically, we can realize that the Participating Modal Mass Ratio-
Oscillating mass participation MPMR and $\%$ Effective volume $(\mathrm{EMM})$ is specified and different amounts $\left(\Sigma \mathrm{m} . \Phi^{2}\right)$ is named as the mass of oscillating shape. In some special cases, the flat problems, so $\left(\Sigma \mathrm{m} . \Phi^{2}\right)=1$; Meantime Participating Modal Mass Ratio $($ MPMR) $=\%$ Effective volume (EMM).In the space problem, the volume of oscillator includes volume fluctuation. In directions $\mathrm{X}, \mathrm{Y}$ and $\mathrm{Z}$-axis torsion oscillators; the sum of the means $=1$; and the value of each is less than 1 . Therefore, it illustrates that the problem is in every respective area (space) which has Participating Modal Mass Ratio (MPMR) $<\%$ Effective volume (EMM). The results from Time History Analysis of participating modal mass ratio (MPMR) showing the first 15 modes of per modal are given below.

Table 7. Square Building with Square Column-MPMR values.

\begin{tabular}{|c|c|c|c|c|c|c|c|}
\hline Mode & Period sec & $\mathbf{U X}$ & $\mathbf{U Y}$ & $\mathbf{U Z}$ & Sum UX & Sum UY & Sum UZ \\
\hline 1 & 2.362 & 0.0139 & 0.7884 & 0 & 0.0139 & 0.7884 & 0 \\
\hline 2 & 2.362 & 0.7884 & 0.0139 & 0 & 0.8023 & 0.8023 & 0 \\
\hline 3 & 1.999 & 0 & 0 & 0 & 0.8023 & 0.8023 & 0 \\
\hline 4 & 0.769 & $1.77 \mathrm{E}-05$ & 0.0974 & 0 & 0.8023 & 0.8997 & 0 \\
\hline 5 & 0.769 & 0.0974 & $1.77 \mathrm{E}-05$ & 0 & 0.8997 & 0.8997 & 0 \\
\hline 6 & 0.656 & 0 & 0 & 0 & 0.8997 & 0.8997 & 0 \\
\hline 7 & 0.441 & 0.0256 & 0.0108 & 0 & 0.9253 & 0.9106 & 0 \\
\hline 8 & 0.441 & 0.0108 & 0.0256 & 0 & 0.9362 & 0.9362 & 0 \\
\hline 9 & 0.381 & 0 & 0 & 0 & 0.9362 & 0.9362 & 0 \\
\hline 10 & 0.3 & 0.0026 & 0.0175 & 0 & 0.9388 & 0.9536 & 0 \\
\hline 11 & 0.3 & 0.0175 & 0.0026 & 0 & 0.9563 & 0.9563 & 0 \\
\hline 12 & 0.261 & 0 & 0 & 0 & 0.9563 & 0.9563 & 0 \\
\hline 13 & 0.22 & $5.05 \mathrm{E}-06$ & 0.013 & 0 & 0.9563 & 0.9693 & 0 \\
\hline 14 & 0.22 & 0.013 & $5.05 \mathrm{E}-06$ & 0 & 0.9693 & 0.9693 & 0 \\
\hline 15 & 0.194 & 0 & 0 & 0 & 0.9693 & 0.9693 & 0 \\
\hline
\end{tabular}

Table 8. Square Building with Rectangular Column - MPMR values.

\begin{tabular}{lllllll}
\hline Mode & Period sec & UX & UY & UZ & Sum UX & Sum UY \\
\hline 1 & 2.857 & 0 & 0.8174 & 0 & 0 & 0.8174 \\
2 & 2.053 & 0.7745 & 0 & 0 & 0.7745 & 0.8174 \\
3 & 1.994 & 0 & 0 & 0 & 0.7745 & 0.8174 \\
4 & 0.945 & 0 & 0.0953 & 0 & 0.7745 & 0.9127 \\
5 & 0.639 & 0 & 0 & 0 & 0.7745 & 0.9127 \\
6 & 0.639 & 0.1034 & 0 & 0 & 0.8779 & 0.9127 \\
7 & 0.556 & 0 & 0.0344 & 0 & 0.8779 & 0.9471 \\
8 & 0.39 & 0 & 0.0181 & 0 & 0.8779 & 0.9652 \\
9 & 0.358 & 0 & 0 & 0 & 0.8779 & 0.9652 \\
10 & 0.342 & 0.0427 & 0 & 0 & 0.9206 & 0.9206 \\
11 & 0.297 & 0 & 0.0112 & 0 & 0 & 0.9652 \\
12 & 0.238 & 0 & 0.0076 & 0 & 0 & 0.9206 \\
13 & 0.235 & 0 & 0 & 0 & 0.9206 & 0.984 \\
15 & 0.215 & 0.0249 & 0 & 0 & 0.9455 & 0.984 \\
\hline
\end{tabular}

Table 9. Square Building with Square Column with FVD - MPMR values.

\begin{tabular}{lllllll}
\hline Mode & Period sec & UX & UY & UZ & Sum UX & Sum UY \\
\hline 1 & 1.427 & $4.26 \mathrm{E}-05$ & 0.6946 & 0 & $4.26 \mathrm{E}-05$ & 0.6946 \\
2 & 1.427 & 0.6946 & $4.26 \mathrm{E}-05$ & 0 & 0.6947 & 0.6947 \\
3 & 0.933 & 0 & 0 & 0 & 0.6947 & 0.6947 \\
4 & 0.311 & 0.0006 & 0.1704 & 0 & 0.6953 & 0.8651 \\
5 & 0.311 & 0.1704 & 0.0006 & 0 & 0.8657 & 0.8657 \\
6 & 0.187 & 0 & 0 & 0 & 0.8657 & 0.8657 \\
7 & 0.122 & 0.0001 & 0.0625 & 0 & 0.9283 & 0.9282 \\
8 & 0.122 & 0.0625 & 0.0001 & 0 & 0.9283 & 0.9283 \\
9 & 0.071 & 0 & 0 & 0 & 0 & 0 \\
\hline
\end{tabular}




\begin{tabular}{lllllll}
\hline Mode & Period sec & UX & UY & UZ & Sum UX & Sum UY \\
\hline 10 & 0.065 & 0.0058 & 0.025 & 0 & 0.9341 & 0.9533 \\
11 & 0.065 & 0.025 & 0.0058 & 0 & 0.9591 & 0.9591 \\
12 & 0.041 & 0.0083 & 0.0088 & 0 & 0.9674 & 0.9679 \\
13 & 0.041 & 0.0088 & 0.0083 & 0 & 0.9762 & 0.9762 \\
14 & 0.038 & 0 & 0 & 0 & 0.9762 & 0.9762 \\
15 & 0.029 & 0.0001 & 0.0101 & 0 & 0.9763 & 0 \\
\hline
\end{tabular}

Table 10. Square Building with Rectangular Column with FVD - MPMR values.

\begin{tabular}{|c|c|c|c|c|c|c|c|}
\hline Mode & Period sec & $\mathbf{U X}$ & $\mathbf{U Y}$ & $\mathbf{U Z}$ & Sum UX & Sum UY & Sum UZ \\
\hline 1 & 1.501 & 0 & 0.6864 & 0 & 0 & 0.6864 & 0 \\
\hline 2 & 1.334 & 0.6957 & 0 & 0 & 0.6957 & 0.6864 & 0 \\
\hline 3 & 0.916 & 0 & 0 & 0 & 0.6957 & 0.6864 & 0 \\
\hline 4 & 0.31 & 0 & 0.1781 & 0 & 0.6957 & 0.8645 & 0 \\
\hline 5 & 0.293 & 0.1699 & 0 & 0 & 0.8656 & 0.8645 & 0 \\
\hline 6 & 0.18 & 0 & 0 & 0 & 0.8656 & 0.8645 & 0 \\
\hline 7 & 0.119 & 0 & 0.0635 & 0 & 0.8656 & 0.928 & 0 \\
\hline 8 & 0.115 & 0.0625 & 0 & 0 & 0.9281 & 0.928 & 0 \\
\hline 9 & 0.068 & 0 & 0 & 0 & 0.9281 & 0.928 & 0 \\
\hline 10 & 0.063 & 0 & 0.031 & 0 & 0.9281 & 0.959 & 0 \\
\hline 11 & 0.061 & 0.0308 & 0 & 0 & 0.9588 & 0.959 & 0 \\
\hline 12 & 0.04 & 0 & 0.0172 & 0 & 0.9588 & 0.9762 & 0 \\
\hline 13 & 0.039 & 0.0172 & 0 & 0 & 0.976 & 0.9762 & 0 \\
\hline 14 & 0.036 & 0 & 0 & 0 & 0.976 & 0.9762 & 0 \\
\hline 15 & 0.028 & 0 & 0.0102 & 0 & 0.976 & 0.9864 & 0 \\
\hline
\end{tabular}

\section{Conclusions}

The fluid viscous damper has produced above than $80 \%$ reduction in Time period of Maximum Pseudo Spectral Acceleration in Response spectrum curves. In the buildings, having Fluid Viscous Damper 250, the base shear has been reduced by $89.49 \%$ for Square Building with Square Column, and $62.79 \%$ for Square Building with Rectangular Column in Time History analysis.

It has been noticed that the structures with square columns performed very well in period of response of the building when compared to structures with rectangular columns regardless of the flooring plan.

In assessing the seismic performance of buildings, the prediction of destruction in buildings is hard to estimate by using pushover analysis method when contrasted with the Time history analysis.

\section{Acknowledgements}

I express my sincere gratitude to my supervisor and guide Prof. $\mathrm{Xu}$ Bin, civil engineering department, Northwestern Polytechnical University, who offered me the valuable guidance, support and advice for the duration of the paper.

\section{References}

[1] M. R. Arefi, "A study on the damping ratio of the viscous fluid dampers in the braced frames," vol. 3, no. 4, pp. 1223$1235,2014$.

[2] J. Marti, M. Crespo, and F. Martinez, "Seismic Isolation and Protection Systems," Seism. Isol. Prot. Syst., vol. 1, no. 1, pp. 125-140, 2010.

[3] M. K. Muthukumar G, "Analytical modeling of damping," indian Concr. J., vol. 88, no. 4, 2014.

[4] K.-H. Chang, Structural Analysis, vol. 163. 2009.

[5] Y. G. Zhao and T. Ono, "Moment methods for structural reliability,” Struct. Saf., vol. 23, no. 1, pp. 47-75, 2001.

[6] V. Umachagi, K. Venkataramana, G. R. Reddy, and R. Verma, "Applications of Dampers for Vibration Control of Structures: an Overview," Int. J. Res. Eng. Technol., pp. 611, 2013.

[7] Ö. Atlayan, "Effect of Viscous Fluid Dampers on Steel Moment Frame Designed for Strength and Hybrid Steel Moment Frame Design,” Environ. Eng., 2008.

[8] A. Chopra, "Dynamics of structures," 2012.

[9] S. Infanti, J. Robinson, and R. Smith, "Viscous Dampers For High-Rise Buildings," 14th World Conf. Earthq. Eng., 2008.

[10] J. Marko, D. Thambiratnam, and N. Perera, "Influence of damping systems on building structures subject to seismic effects,” Eng. Struct., vol. 26, no. 13, pp. 1939-1956, 2004.

[11] V. S. Balkanlou, M. R. Bagerzadeh, B. B. Azar, and A. Behravesh, "Evaluating Effects of Viscous Dampers on optimizing Seismic Behavior of Structures," no. 2007, 2013.

[12] S. Amir and H. Jiaxin, "Optimum Parameter of a Viscous Damper for Seismic and Wind Vibration," vol. 8, no. 2, pp. 192-196, 2014.

[13] B. S. Taranath, Reinforced Concrete Design of Tall Buildings.

[14] LIYA MATHEW \& C. PRABHA, "Effect of Fluid Viscous Dampers in Multi-Storeyed Buildings," IMPACT Int. J. Res. Eng. Technol. (IMPACT IJRET), vol. 2, no. 9, pp. 59-64, 2014. 
[15] R. Gettu and M. Santhanam, "Retrofit of non-engineered buildings," Handb. Seism. retrofit Build., no. April, p. 471, 2007.

[16] J. Otten, J. Luntz, D. Brei, K. A. Strom, A. L. Browne, and N. L. Johnson, "Proof-of-Concept of the Shape Memory Alloy ReseTtable Dual Chamber Lift Device for Pedestrian Protection With Tailorable Performance," J. Mech. Des., vol. 135, no. 6, p. 61008, Apr. 2013.
[17] ASCE 7-98, 1998. Minimum Design Loads for Buildings and Other Structures. American Society of Civil Engineers.

[18] R. K. Goel, C. A. Booker, "Inelastic seismic response of asymmetric systems", Earthq Eng Struct Dyn, vol. 30, 2001.

[19] Design Formulations for Supplemental Viscous Dampers to Building Structures. 